1

2

3

4

5

6

7

\title{
INFORMING THE STRATEGIC ROLLOUT OF FAST ELECTRIC VEHICLE CHARGING NETWORKS WITH USER CHARGING BEHAVIOUR DATA ANALYSIS
}

Patrick Morrissey,

Centre for Transportation Research

Dept of Civil, Structural \& Environmental Engineering

Trinity College Dublin

Dublin 2

Tel: + 35318962084

Fax: + 35316773072

Email: morrispj@tcd.ie

Peter Weldon

Centre for Transportation Research

Dept of Civil, Structural \& Environmental Engineering

Trinity College Dublin

Dublin 2

Tel: + 35318962537

Fax: + 35316773072

Email:weldonp@tcd.ie

Margaret O'Mahony (Corresponding author)

Centre for Transportation Research

Dept of Civil, Structural \& Environmental Engineering

Trinity College Dublin

Dublin 2

Tel: + 35318962537

Fax: + 35316773072

Email: Margaret.omahony@tcd.ie

Published as: Morrissey, P., Weldon, P. and O’Mahony, M. Informing the strategic rollout of fast electric vehicle charging networks with user charging behaviour data analysis. Transportation Research Record, 2016, 2572, 9-19. DOI: 10.3141/2572-02 


\begin{abstract}
With the current range limitations of existing electric vehicle (EV) technology, range anxiety has been identified as one of the main barriers to their adoption. For countries or states which are predominantly rural in nature, with few major urban areas, this range limitation has the potential to be a greater barrier than in the case of large cities. This paper presents data recorded in Ireland on the spatial usage patterns of an existing fast charging network over an extended period. These data are used to assess how the infrastructure is being used currently and, in particular, examines the issues relating to urban versus rural usage patterns. Existing infrastructure rollout strategies are examined in the context of the main findings from this analysis and a spatial density analysis is presented to examine how a desired density can influence a rollout strategy. It was found that urban users have very different fast charging requirements compared to rural and commuter groups. Urban users tend to charge their vehicles close to their home as a means of extending their local EV range. EV users from other geographic areas tend to charge their vehicles further from their home. Based on the findings of this work, it would appear that current rollout strategies based primarily on 'electric' highway corridors may not be appropriate for all EV users and different infrastructure rollout strategies based on fast charging facility densities and geographic location may be more appropriate.
\end{abstract}

Keywords: Fast charging, electric vehicles, charging infrastructure 


\section{INTRODUCTION}

Fast (DC) charging will be a key factor in successfully achieving a significant and sustainable quantity of electrically powered vehicles in the short- to medium-term. It has been noted that fast charging may not be economically viable for large scale rollout in the short to medium term due to the projected low adoption rates of electric vehicles (EV) (1). However, one of the main barriers to EV adoption is the perceived range limitations of the current generation of EVs and therefore there is a need for a connected network of charging infrastructure to encourage large scale adoption (2). Previous research has indicated the beneficial local effects of DC fast chargers to EV users in order to reduce range anxiety concerns (3).

The difficulty in predicting the future timings and magnitudes of EV fast charging events is well established, and recently probabilistic statistical approaches have been proposed for better future planning $(4,5)$. Previous studies have omitted historical data because of lack of availability. Assumed similarities to internal combustion engine vehicle (ICEV) behaviour and/or simulations based on predictive user behaviours have been used instead $(4,6)$. These charging demands and profiles can then be used to better solve optimisation algorithms in order to recommend (fast) charging facility deployment strategies (7).

Less granular approaches have also been proposed; for example, one approach approximated the maximum total power requirement from fast charging facilities based on an arbitrary EV market penetration and then divided this by the nominal power assignment of a fast charging unit $(5,4)$. This approach does not however take into account the required geographical spread of the infrastructure, but rather presents a good starting point for large scale infrastructural planning. Other research used GIS information and multi-criteria analysis to produce optimal charging facility locations (8). This approach did not distinguish between fast and slow charging infrastructure and again was not informed by historical user data. It has been suggested by others that existing car-parking demand data can be used within urban areas to determine optimal locations for the charging infrastructure (9); however this approach may be less applicable to a fast charging network. Other research considered that near-home and adjacent-region corridors were the optimum locations for any future fast charging network (10).

Other studies have been generally focused on determining absolute minimum fast charging infrastructure needs (e.g. in a U.S. State or optimal charging station densities for a country) or optimising the location of charging facility development on networks $(11,12)$ with a strong focus on highway corridor charging infrastructure evident to date. Another approach illustrates the highway based approach where only primary and secondary roads were considered in the model and demands were assigned to roads based on road lengths and relevant other parameters (13). A route-based flow capture model through a multi-step process was used to determine the required number and location of fast chargers for the state of California, USA (12). The study concluded that an initial 200 fast charging units would suffice for the state of California with the network likely being required to grow further thereafter to avoid congestion. Whilst this approach maximised the achievable travel distances on the road network for EV users, no historical usage data for fast chargers were used in calibrating the model.

Models relating to fast charging networks can be further complicated when the potential impacts on the local power supply grid are considered (14). Due to the lack of availability of input data, other work proposed an approach for estimating fast charger requirements based on desirable facility densities (11). This approach is more simplistic and requires less data inputs or assumptions to be made but again lacked historical usage data as an input. 
1 While novel models and approaches have been proposed for future strategic fast charger 2 deployment, the absence of real data to calibrate and inform these approaches is a potential 3 issue that could affect accuracy in prediction and more importantly the individual requirements 4 of EV users. As the EV landscape matures, historical usage behaviour will become more 5 readily available and this is evidenced by other research where data on charging behaviours for 6 a number of country-wide charging infrastructure networks in the USA were presented (15). 7 However, there is very little research conducted to date using real historical fast charging data 8 as an input to a strategic and optimum fast charger location deployment strategy.

9 Ireland is in a unique position to encourage the use of EVs due to it being an island nation with 10 relatively short travel distances between major cities and relatively large commuter belts surrounding cities. In addition, current and proposed increases in the availability of renewable electricity (predominantly from wind) allow for the further development of green driving and carbon savings when compared to ICEVs. In comparison to other countries, Ireland has a more rural and sparsely spread population with the exception of the greater Dublin area and some smaller cities. The latest census of Ireland data identified that over 1.9 million people live in county Dublin and the four counties immediately adjacent to it (these four counties will be referred to as commuter counties throughout this paper), which amounts to over $40 \%$ of the entire country's population (16) - a map of Ireland showing the location of Dublin city, Dublin County and the surrounding commuter counties is given in Figure 1(a). In comparison there are 2.69 million people living in the remaining 21 counties. This urban/rural divide allows for comparisons to be made in user behaviour.

This paper will conduct an analysis of fast charging event data recorded by data loggers situated in fast charging facilities located throughout Ireland. Any trends observed concerning the usage of the fast charging network will then be used to inform strategic rollout of future fast charging facilities, particularly in the context of the urban/rural divide. The main focus of this paper will be on how the infrastructure is being used spatially by existing EV users. Whilst the dichotomy between the usage of fast charging infrastructure as a local every-day range extender and as an occasional inter-city travel enabler may be expected, this paper will develop and expand upon this dichotomy in a geographical context through the usage of real EV user charging data emerging from fast charging infrastructure, which in turn can inform future fast charging infrastructure deployment. As previously discussed, the focus of other approaches for infrastructure rollout was on highways and at hubs that would increase and extend the range available to users. An attempt will be made to validate this approach or alternatively propose a new approach should the analysis indicate it necessary. Finally, policy recommendations will be made based on the outcomes of the analysis. 


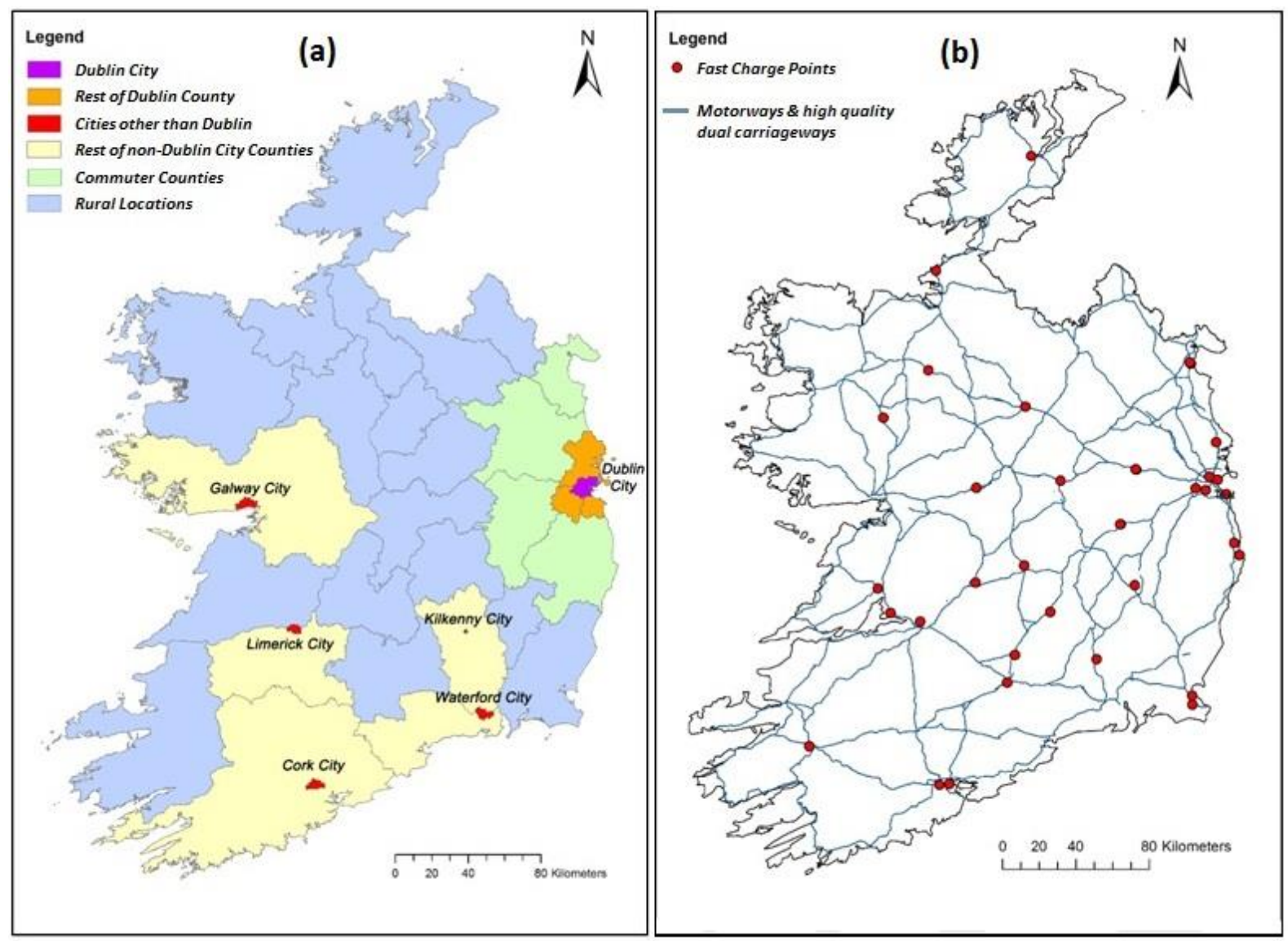

FIGURE 1 Maps of Ireland showing (a) the location of major cities and the geographic groups used in the analysis within this study, and (b) the fast charge points monitored during the study with the location of motorway and high quality dual carriageways shown

\section{METHOD}

\section{Data Availability}

A total of 37 charge points were monitored during the analysis period in Ireland. The data available cover the time period between February 2013 and March 2015 and data were also available for monthly and yearly EV sales during this period. The monitored fast chargers have an input/output nominal power of either $43 \mathrm{~kW}$ or $50 \mathrm{~kW}$, delivering the charge through direct current (DC) and through three-phase electric power. They are primarily located in service stations along Ireland's motorways, with additional fast chargers situated in public car parks, and this is in line with the Electricity Supply Board's (ESB) policy of creating 'electric corridors' along key inter-urban routes and between cities and towns (17). A map showing the locations of the fast chargers monitored in the study and the major highways in the country is given in Figure 1(b).

In addition to the charge point usage data, locational information was also available for EV user Tag-IDs which allowed a spatial analysis to be carried out. Detailed user information such as age and gender or details relating to the specific purpose for trips was not available. This is due to strict data confidentially agreements between the service provider and individual users. For each charge event, the data loggers recorded: start and finish date/time; the unique EV user 
Tag-ID; and the quantity of power consumed $(\mathrm{kWh})$. Road network data were utilised in the study, obtained from the Irish standardised digital referencing framework known as 'Prime2' (18), and this enabled analysis of the road network in the Geographical Information System (GIS) software package ArcGIS 10.1 (19) to an accuracy of $1 \mathrm{~m}$. Prime2 is an object orientated, seamless topographic database of 3D geometry without any generalisation and has been developed by the OSi (18) using an Open Geospatial Consortium (OGC) simple feature model which follows the ISO 19115-1:2014 (20) standard for metadata. The road network was modelled in Prime2 according to the Geographic Data Files (GDF) ISO data standard (21).

\section{Spatial Data Analysis}

The data analysis was focused on the spatial nature of the charge events to determine how the existing infrastructure was being used by current EV users. GPS location data were available for each of the fast chargers and these were assigned to each fast charger using a unique ID code. GPS co-ordinates were assigned to each of the 966 Tag-IDs based on user addresses; it must be noted that in order to preserve data confidentiality and anonymity of the EV users, this process was carried out in a controlled manner with all personal information being removed once the relevant analysis was performed.

The travel distance between the GPS co-ordinates of the Tag-ID home address and the fast charger GPS co-ordinates were then calculated via the road network. The OSi roadmap data were imported into ArcMAP 10.1 (19) and a network was created with nodes at intersections using Network Analyst. Network Analyst is a spatial analysis tool contained within ArcMAP 10.1 (19) which solves network routing problems. A PYTHON scripting code was used to calculate travel distances between GPS co-ordinates via the road network using the shortest distance approach - the calculated value was given the name 'distance from home'

Each EV user home address was categorised based on location. Two scenarios were considered:

I. A comparison between urban and rural location-based users and the specific characteristics of each group's charging behaviour. Urban locations were defined as addresses which fell within a town or city with a population exceeding 10,000 persons. Population information for this assignment was acquired from the most recent census of Ireland data in 2011 (16).

II. The data were further segregated to involve 6 geographic groups of interest with home locations in:

1. Dublin City only

2. The rest of Dublin county excluding city locations

3. Other cities across Ireland - the cities of Galway, Waterford, Limerick, Kilkenny, Cork

4. The rest of the counties containing each of the cities listed in (Group 3) above

5. Dublin city commuter counties - counties immediately adjacent to Dublin county; counties Kildare, Meath, Louth and Wicklow

6. Rural locations - the remaining locations were deemed to be rural

The locations of these geographic groups relative to each other are shown in Figure 1(a) and the outcomes of these analyses are presented in the results section. 


\section{Model Development \& Implementation}

2 Each of the fast charge points were considered as a facility providing a service and this

3 approach allowed the use of the 'serviceable area' analysis tool. It calculates a polygon area of 4 the transportation network which can be serviced by a facility based on a number of input 5 criteria. The following criteria were used: polygons were calculated assuming travel towards 6 the facilities; U-turns on the network were allowed; elevations at junctions and slip-roads were 7 ignored; and the default search tolerance was allowed for finding network locations (i.e. charge 8 points not located directly on the road network). The impedance of a network, as defined by 9 ArcGIS, is the amount of resistance or cost required to traverse a path in a network, or to move from one element in the network to another, and the resistance can be a measure of travel distance, time, or other metrics, with a higher impedance indicating more resistance to movement and the optimum path in a network represented by the path of lowest impedance (22). Within the current study, the impedance is the distance that can be traversed via the road network to the facility. The impedance was varied from a minimum distance of $10 \mathrm{~km}$ up to a maximum of $80 \mathrm{~km}$. The serviceable area is the area around the charge point which includes all possible routes within the selected impedance level.

\section{RESULTS}

\section{Overall Charging Trends}

20 The average number of charge events per fast charging unit per day ranges between 0.03 and 10 uses per day with a mean confidence interval (CI) of $1.07 \pm 0.49$ uses per fast charge point per day. The high standard deviation of 1.85 indicates that some fast charging units are used far more frequently than others. Figure 2 shows how the total number of charge events has increased as the number of EVs registered in Ireland has increased (data are for the period between February 2013 and March 2015). Correlation and regression analyses were carried out on 1) the number of charge events and 2) the number of charge events per charger per day with the number of EVs registered in each case. High correlation rates were found ( 0.97) and the regression analysis (Figure 2) shows the strong linear relationship between the two charge event variables and the number of EVs in the country. 
1

2 FIGURE 2 Regression analyses of the infrastructure usage and the number of EVs in 3 the country

4 Although the focus of this study was not to predict the impacts of fast charging on the existing 5 electrical grid, it is important that studies such as this consider the likely energy requirement 6 from charging infrastructure over the course of the day. An understanding of the likely energy 7 requirement informs relevant stakeholders of how charging activity may impact the grid, 8 particularly during peak grid demand periods. A distribution of the number of charging events 9 that occurred for each hour of the day with the corresponding total $\mathrm{kWh}$ of charging by hour 10 of the day that was observed during this study is given in Figure 3 below. It can be seen that peak energy demand occurs during the period between 17:00 - 19:00 which corresponds with the peak energy demand on the electrical grid.

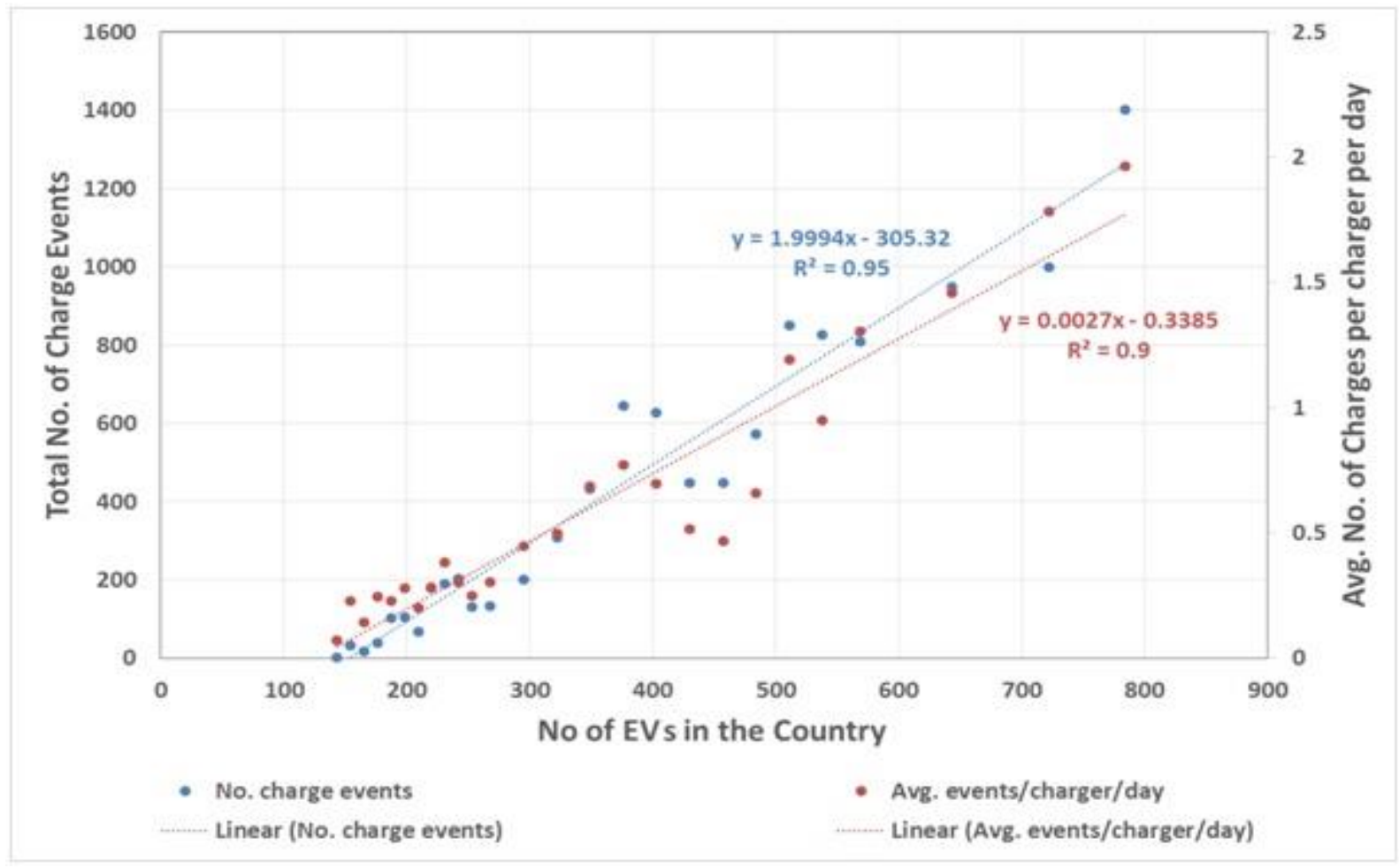




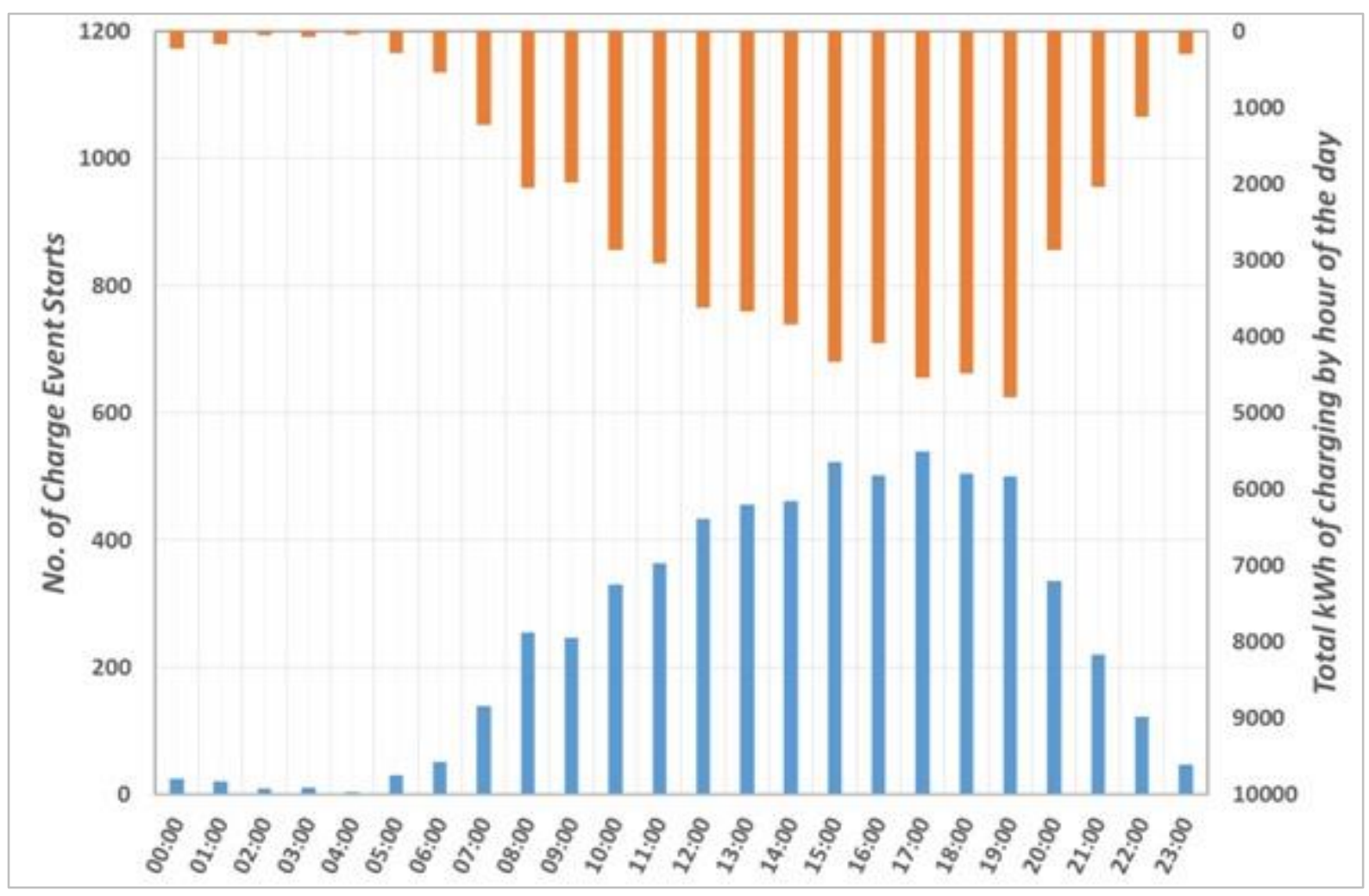

FIGURE 3 Distribution of the number of charging events that occurred for each hour of the day (primary $\mathrm{y}$-axis) with the corresponding total $\mathrm{kWh}$ of charging by hour of the day also shown (secondary y-axis)

6 Spatial Charging Behaviour

7 Overall summary statistics regarding how the fast charging network is being used are provided 8 in Figure 4 below along with a distribution of the distance from home values in $50 \mathrm{~km}$ bands. 9 The average distance from home was $66.58 \mathrm{~km}$ when a fast charging event took place. It can 10 be seen that the $3^{\text {rd }}$ quartile value is $88.4 \mathrm{~km}$ indicating that the majority of fast charging events 11 took place relatively closer to the home location when compared with average electric vehicle ranges $(100-180 \mathrm{~km})$. It can also be seen that almost $60 \%$ of fast charging events took place less than $50 \mathrm{~km}$ from the EV home location. 


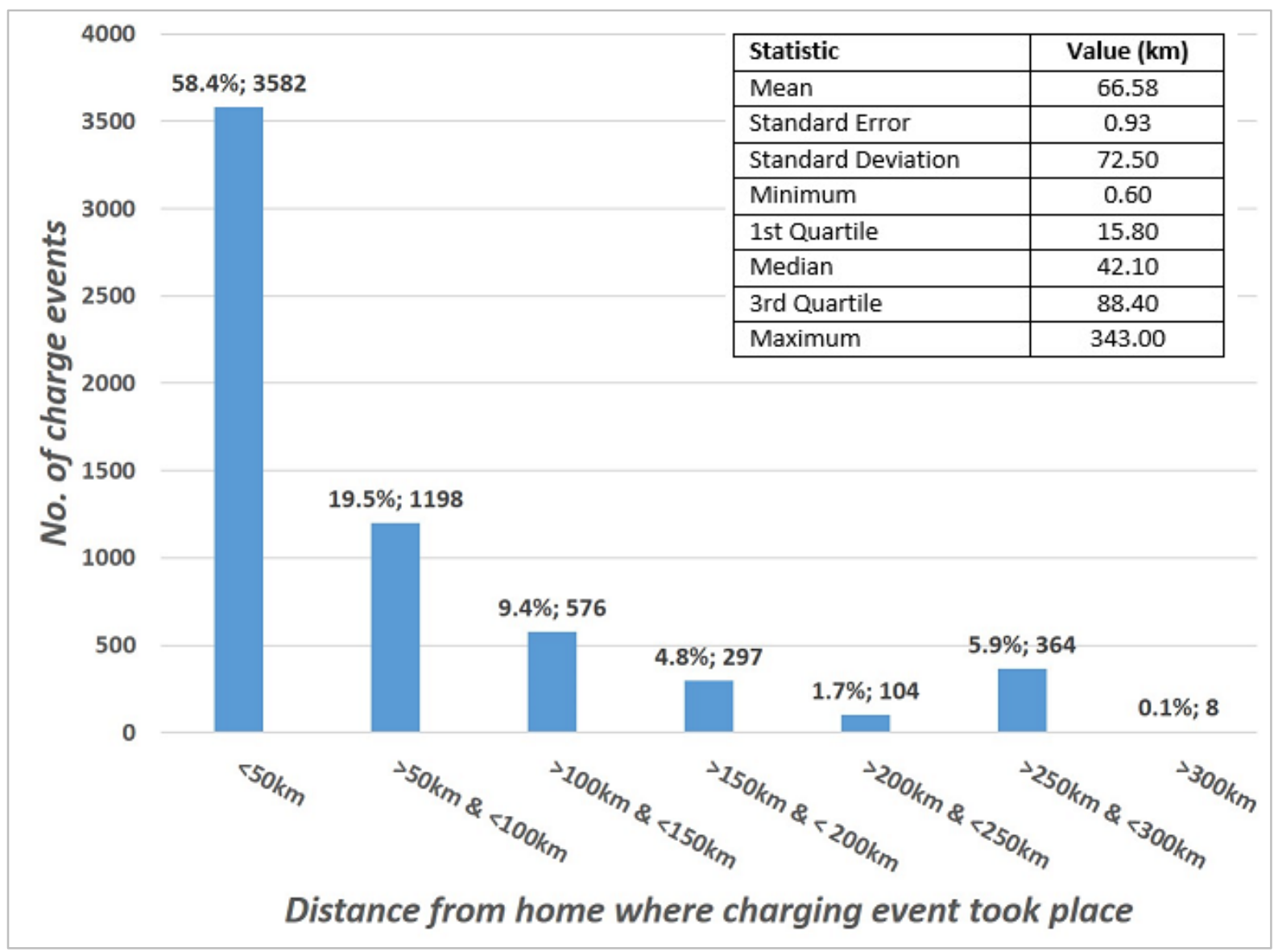

Note: 1 mile $=1.61 \mathrm{~km}$

\section{FIGURE 4 Summary statistics and distribution of the number of charge events that took place in $50 \mathrm{~km}$ distance bands from the home location of the electric vehicle user shown on the $\mathrm{x}$-axis}

In order to further investigate patterns into user charging behaviours, charging events were additionally separated into first charging event per user per day and later second and subsequent charging events. First and subsequent charging event timings were then counted for occurrences during three hourly time slots over the day and the results were separated into the distance from home bands shown in Figure 4. The results of this analysis are given in Figure 5 below, with Figure 5(a) showing first charge events of the day and Figure 5(b) displaying subsequent charging events during the day. As seen in Figure 5, there is evidence that fast charging close to home is used later in the day (possibly to top up an EV battery on the way home from work) with peaks in the number of charging events occurring less than $50 \mathrm{~km}$ from home occurring in the 15:00 - 18:00 time slots. However, when examining the timing of the occurrences of second and subsequent charging events it can be seen that the $50-100 \mathrm{~km}$ and $100-150 \mathrm{~km}$ groups record peaks in the 15:00 - 18:00 and 18:00 - 21:00 time slots indicating that longer journeys are also being made by utilising the fast charging infrastructure. 

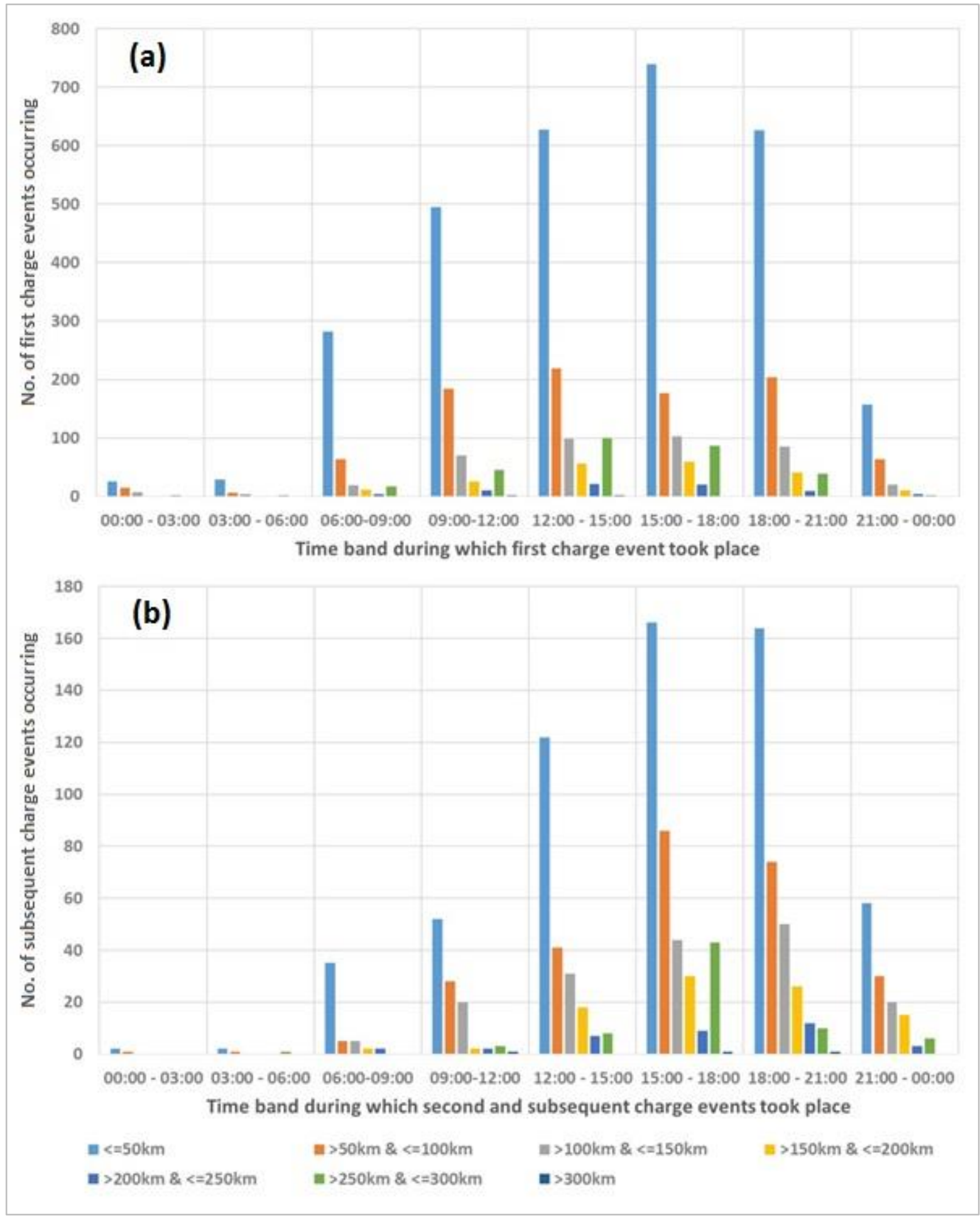

2 FIGURE 5 Distribution of the number of fast charging events occurring during three 3 hourly slots over the day segregated by the distance from home that the charge event took 4 place; occurrences have been broken into two groups: (a) first charge time per user per 5 day and (b) second and subsequent charge times per user per day

6 In order to identify further trends in the spatial usage of the fast charging infrastructure, 7 independent two sample t-tests were carried out between urban and rural EV user groups as 8 outlined earlier, considering both charge consumption and distance from home variables. 9 Statistically significant differences were found between the two groups for both variables with 
p-values of less than 0.05 found in both cases. Urban users were found to have a slightly higher mean charge consumption of $8.73 \pm 0.22 \mathrm{kWh}$ compared to rural users $(8.42 \pm 0.16 \mathrm{kWh}(\mathrm{p}=$ $0.028)$ ). Rural users were found to undertake a fast charging event further from their home address with a mean of $77.51 \pm 2.45 \mathrm{~km}$ compared to a significantly lower mean value for urban users of $47.55 \pm 2.37 \mathrm{~km}$ ( $\mathrm{p}<0.005)$. The results of the simple comparison (Scenario 1) between urban and rural EV users highlight that rural EV users undertake fast charging events further from their home location indicating longer trips are made which require the fast charging infrastructure to be utilised. In this regard it can be determined that rural EV drivers choose to charge farther from home due to their geographic circumstances when compared to urban EV users.

Scatter plots of each of the variable relationships were produced for the charge consumption against distance from home for the scenarios mentioned; the plot for Scenario 2 is presented below in Figure 6. A wide variation of spread is observed between the two parameters with no clear distinctions obvious between city, commuter or urban areas.

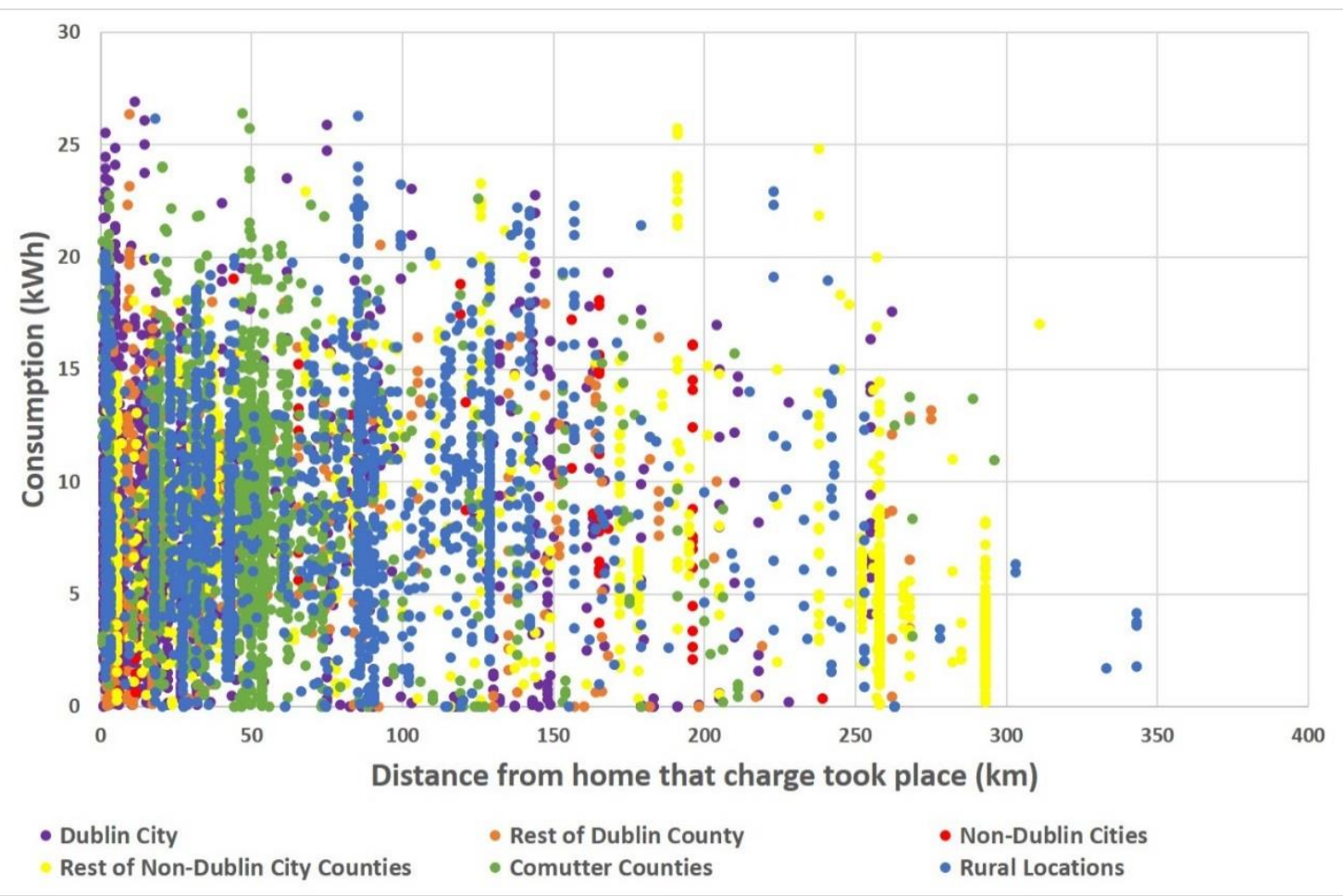

Note: 1 mile $=1.61 \mathrm{~km}$

FIGURE 6 Scatter plot of distance from home values against the corresponding charge consumption for each of the six geographic groups (Scenario 2)

More detailed investigation was conducted on the 6 geographic groups of data (as described earlier in Scenario 2) and summary statistics were produced for the same two variables - see Table 1 below for details. Charge consumption values ranged between 7.16 and $9.6 \mathrm{kWh}$, with Dublin county (excl. Dublin city) recording the lowest mean consumption value and rural locations the highest. It can also be seen that Dublin city- and county-located EV users recorded the lowest distance from home values of 39.63 and $33.73 \mathrm{~km}$ respectively. In 
comparison, city locations and the associated counties recorded the highest distance from home values of 128.19 and $143.35 \mathrm{~km}$ respectively.

TABLE 1 - Spatial usage statistics of the fast charging network for each of the geographic groups segregated by home location during the monitored period (Scenario 2)

\begin{tabular}{|l|r|r|c|c|c|c|c|}
\hline \multirow{2}{*}{ Home Location } & \multirow{2}{*}{$\begin{array}{l}\text { No. of } \\
\text { observations }\end{array}$} & \multicolumn{3}{|c|}{ Consumption [kWh] } & \multicolumn{2}{c|}{ Distance from Home [km] } \\
\cline { 3 - 9 } & $\begin{array}{c}\text { Mea } \\
\mathbf{n}\end{array}$ & $\begin{array}{c}\text { Std. } \\
\text { Dev. }\end{array}$ & $\begin{array}{c}\text { Std. } \\
\text { Error }\end{array}$ & Mean & $\begin{array}{c}\text { Std. } \\
\text { Dev. }\end{array}$ & $\begin{array}{c}\text { Std. } \\
\text { Error }\end{array}$ \\
\hline Dublin City & 1,346 & 8.43 & 5.43 & 0.15 & 39.63 & 54.94 & 1.50 \\
\hline $\begin{array}{l}\text { Rest of Dublin } \\
\text { county }\end{array}$ & 732 & 7.16 & 4.47 & 0.17 & 33.73 & 52.14 & 1.93 \\
\hline $\begin{array}{l}\text { Galway/Waterford } \\
\text { /Limerick/Kilkenny } \\
\text { /Cork Cities }\end{array}$ & 61 & 9.47 & 5.38 & 0.69 & 128.19 & 64.57 & 8.27 \\
\hline $\begin{array}{l}\text { Rest of counties } \\
\text { Galway/Waterford } \\
\text { /Limerick/Kilkenny } \\
\text { /Cork }\end{array}$ & 918 & 7.42 & 4.83 & 0.16 & 143.35 & 107.69 & 3.55 \\
\hline $\begin{array}{l}\text { Dublin Commuter } \\
\text { Counties }\end{array}$ & 1,361 & 8.74 & 5.08 & 0.14 & 53.30 & 37.49 & 1.02 \\
\hline Rural Locations & 1,711 & 9.60 & 5.27 & 0.13 & 69.00 & 57.75 & 1.40 \\
\hline
\end{tabular}

Note: 1 mile $=1.61 \mathrm{~km}$

One-way ANOVA tests were carried out comparing between the 6 geographic groups for the same two variables. For charge consumption, an F-value of $35.09(\mathrm{p}<0.05)$ was found with 5 degrees of freedom (df); however the effect size of 0.028 indicated that much of the variation was within group. In the case of distance from home, an F-value of $382.11(\mathrm{df}=5)(\mathrm{p}<0.05)$ was found, with a large effect size of 0.23 , indicating a highly statistically significant between group difference. Aligned to the ANOVA tests, CIs were calculated and additionally a multiple comparison test was carried out whereby the mean difference of each group mean from the other group means was calculated. Plots illustrating each of the resulting mean and mean difference CIs are given in Figure 7 below.

Referring to Figure 7(a), it can be seen that when only the group mean CIs are examined (shown in black in Figure 7(a)) 4 group CIs overlap with a further two group CIs overlapping separately. The two group CIs that overlap independently of the others are the 'Rest of Dublin County' and 'Rest of Non-Dublin City Counties' geographic locations. Both of these groups contain EV users that live in a county that contains a city and it can be seen that their mean charge consumption values are lower than the other four groups. A comparison of the associated mean difference CIs (also contained on Figure 7(a)) identifies that whilst these groups do have lower mean consumption values, the difference from the other 4 groups is weak statistically as the mean difference CIs overlap with other groups and this confirms the weak effect size found in the ANOVA test. 


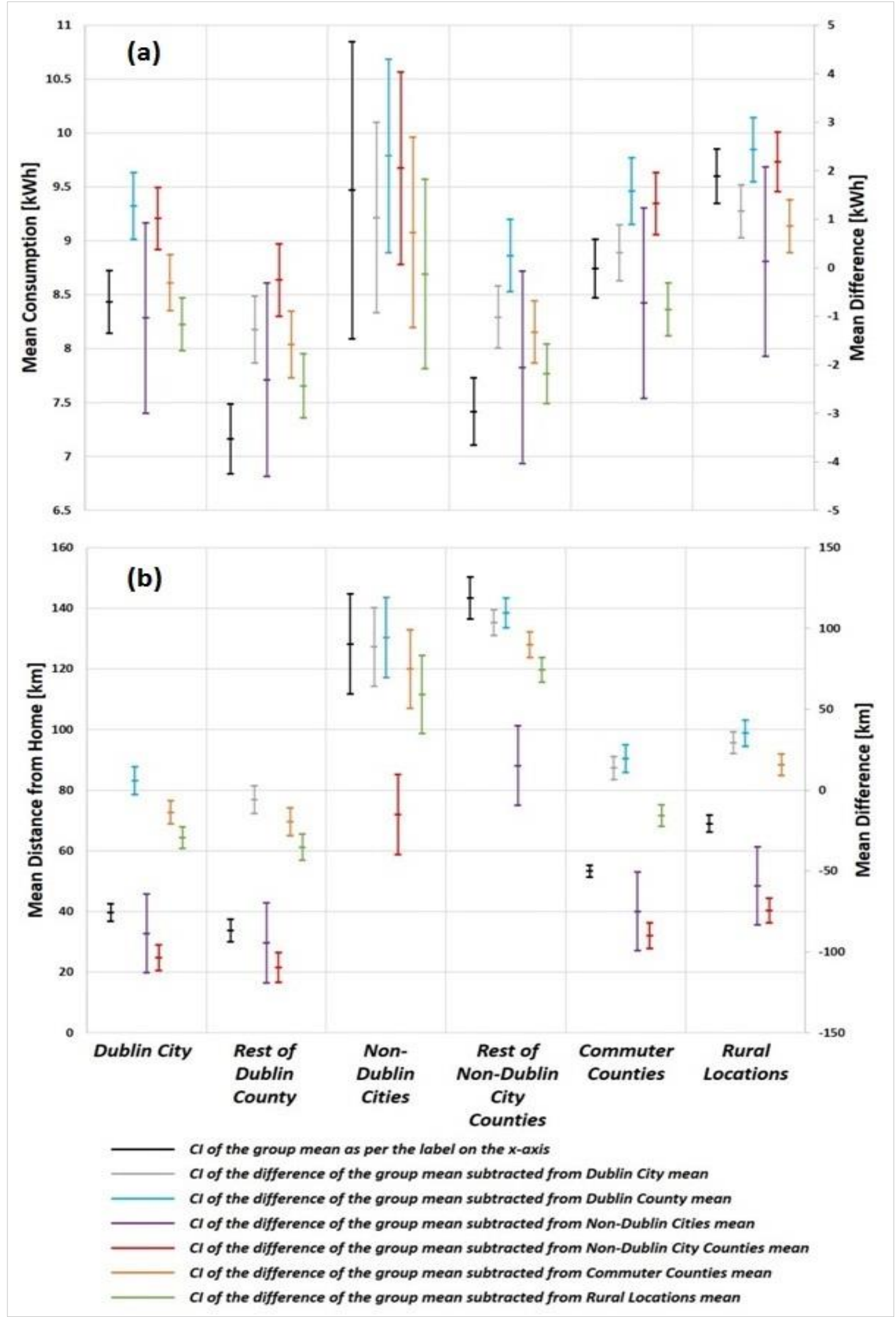
Note: 1 mile $=1.61 \mathrm{~km}$

FIGURE 7 Confidence intervals for (a) mean charge consumption values and (b) mean distance from home values of each of the geographical groups with confidence intervals of the mean difference between groups plotted on a secondary axis 
The CIs for mean distance from home values for the 6 geographic groups given in Figure 7(b) reveal interesting results. When only the group mean CIs are examined (shown in black in Figure 7(b)), 4 different groups emerge where CIs do not overlap. Two sets of two groups have overlapping CIs, the first of which contains both 'Dublin City' and 'Dublin County' addresses with these two groups having the lowest mean values. The two groups that recorded the highest CIs were also grouped together and these two groups were 'Non-Dublin cities' and 'Rest of Non-Dublin City Counties'. The remaining two group CIs did not overlap with any other group and this illustrates the high degree of difference between them and the other groups. Comparing the associated mean difference CIs (also contained in Figure 7(b)) identifies clear trends when comparing between groups. The mean difference CIs of the Non-Dublin cities and their associated counties (Rest of non-Dublin City counties) overlap consistently when their group mean is subtracted from each of the other groups - shown in purple and red in Figure 7(b) above. Similarly 'Rural' and 'Commuter County' group mean difference CIs are paired together, as are 'Dublin City' and 'Rest of Dublin County' mean difference CIs.

Referring to Figure 1(a) and Figure 1(b), it can be noted that the circumstances of Galway and Waterford cities may not reflect the circumstances of Cork, Limerick, and Kilkenny cities with respect to the availability of fast charging infrastructure, in that the nearest fast chargers are far from Galway and Waterford cities whilst there are chargers within Cork, Limerick, and Kilkenny cities. In order to explore potential differences between these locations, additional analysis was conducted which expanded the number of geographic groups from six to eight by dividing the "Non-Dublin Cities" and "Rest of Non-Dublin Counties" groups between the aforementioned cities. Results of the statistical analyses for the "charge consumption" and "distance from home" metrics for the eight geographic groups were almost identical to the results generated for the six geographic groups, which further highlights the previously discovered geographic differences in EV user behaviours.

\section{Fast Charging Infrastructure Density}

In order to identify the effects of varying the density of fast charging units across the country, the network analyst tool within ArcGIS 10.1 was used to calculate serviceable areas for each of the existing fast charger locations. An initial impedance value of $10 \mathrm{~km}$ was used initially and this impedance was increased incrementally by $10 \mathrm{~km}$ to a maximum of $80 \mathrm{~km}$ - sample outputs from the analysis are given in Figure 8. Referring to Figure 8(b), at an impedance of $40 \mathrm{~km}$ the resulting serviceable areas from the existing fast charging infrastructure provides coverage to almost $80 \%$ of the country's road network. The serviceable areas at an impedance of $60 \mathrm{~km}$ are shown in Figure 8(c) below, giving 90\% of the country's road network access to the fast charging network.

In order to determine a desirable density for the fast charging network, a key criterion is the acceptable travel distance (or impedance in this analysis) that users must traverse to reach a facility. To determine an appropriate density for chargers, Sathaye \& Kelley (11) used an approach based on population densities and road highway corridors using varying maximum allowable distances that an electric vehicle may travel to reach a charging location as a basis for charging facility planning. Using their lowest allowable travel distance between charging facilities of $24 \mathrm{~km}$ as input to this work, it was found that $35 \%$ of the country's road network can access a fast charging facility at this impedance value (Figure 8 (a)). 


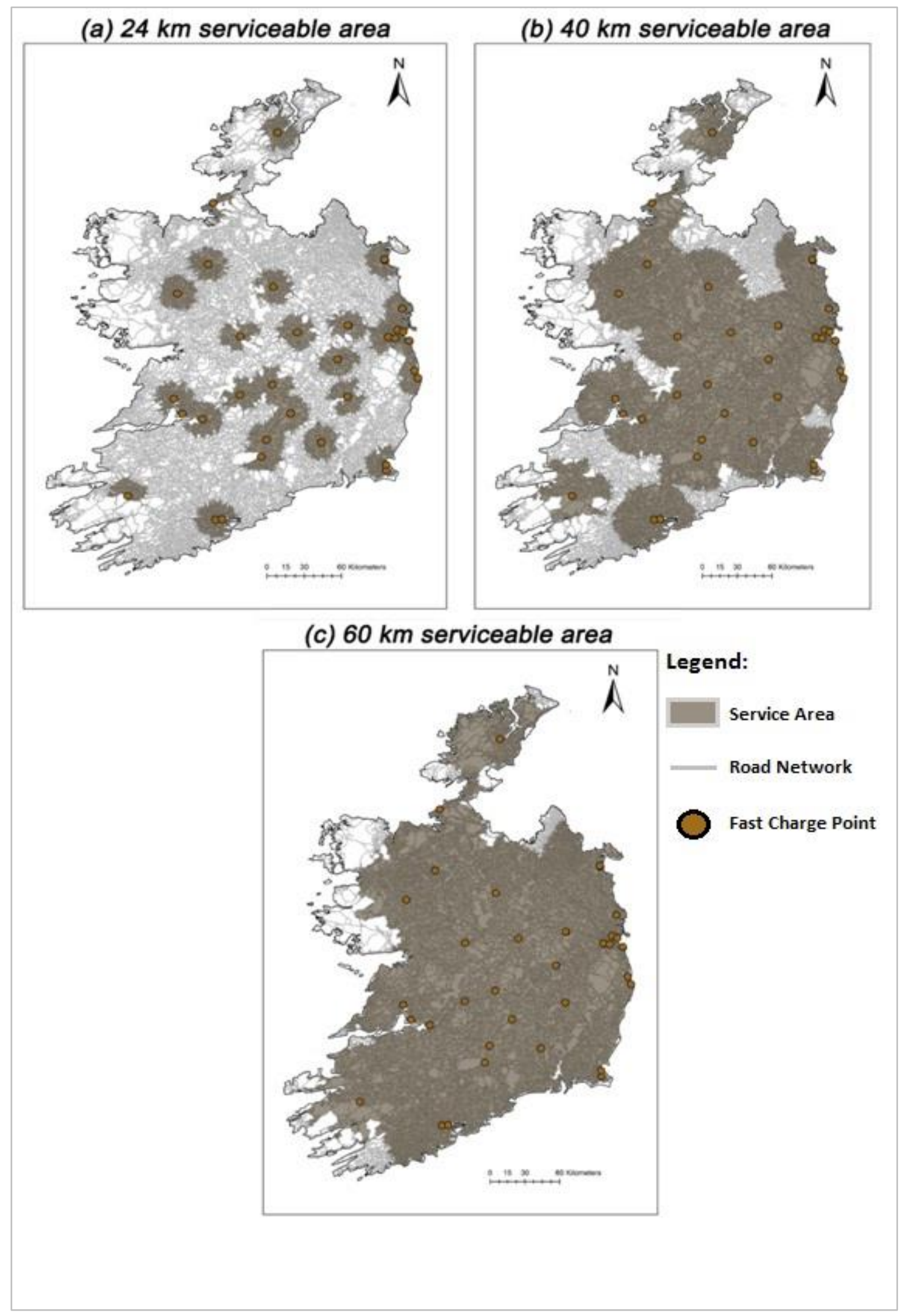

Note: 1 mile $=1.61 \mathrm{~km}$

FIGURE 8 Serviceable areas as calculated in network analyst for impedance values of (a) $24 \mathrm{~km}$ (b) $40 \mathrm{~km}$ (c) $60 \mathrm{~km}$ 


\section{DISCUSSION}

2 As discussed earlier, the most common approach to date for the rollout of fast charging 3 infrastructure has been to concentrate on highway corridors which in theory should allow 4 longer trips to be undertaken and increases EV users' potential journey ranges. However the 5 results shown in this study appear to show a more varied usage requirement from EV users. It 6 was found that the average distance EV users were from home when using a fast charger was $7 \quad 66.6 \pm 1.8 \mathrm{~km}$ and this value is considerably lower than the typical range of a standard EV. Fifty 8 eight per cent of all fast charging events took place less than $50 \mathrm{~km}$ from the EV users' home 9 location and this could suggest that EV users may be using fast chargers to extend their local

When examining the spatial usage patterns depending on geographical location, other trends were observed. Rural users recorded a mean distance from home value of $77.51 \pm 2.45 \mathrm{~km}$ compared to a significantly lower mean value of $47.55 \pm 2.37 \mathrm{~km}$ recorded by urban users. Further segregation of the data into geographic groups again revealed interesting results. Dublin city and county have the highest population densities in the country of Ireland with almost $30 \%$ of the population living there. Those users recorded the lowest mean distance from home values of $39.63 \pm 2.94$ and $33.7 \pm 3.78 \mathrm{~km}$, respectively. In comparison, other city locations around the country and the associated counties recorded the highest distance from home values of $128.19 \pm 16.2$ and $143.35 \pm 6.96 \mathrm{~km}$, respectively. The wide range observed suggests that while the highway corridor approach to siting infrastructure might be appropriate for more rural and commuter EV users it would seem not to serve urban users to the same extent. It can additionally be noted that the similarity of the consumption values relative to the distance from home values for the "Non-Dublin Cities" group and the "Rest of Non-Dublin Counties" group implies that second or subsequent charges are occurring for vehicles within these groups, further suggesting that the highway corridor deployment approach may be more appropriate for more rural EV users.

The usage frequency of the fast charging infrastructure is currently low (an average of 1.07 charge events per charge point per day); however, as the market share increases it would be possible to estimate the usage frequencies of the network given the relationships found during this study. The regression analysis presented within this study provided information on the strong relationships between the number of EVs within the country and both the average number of charge events per charge point per day and the total number of charge events, facilitating predictions for these charging event frequency variables. The results from the network analyst analysis indicated that the current fast charging infrastructure in Ireland is adequate to service the majority of the country's road network at an impedance value of $60 \mathrm{~km}$. Should no new facilities be added in the short to medium term, the usage frequencies of the infrastructure will become more important than charger density. Predicting the likelihood of an EV user being able to access an available fast charging unit in the future when the total number of EVs has increased significantly will therefore become more pertinent. On the basis of the regression analysis presented earlier, projections of 100,000 fast charging events for a total EV fleet of 50,000 vehicles can be made. The Irish government has set a target of 50,000 EVs in Ireland by the year 2020 (23). On the basis of an average charging event for a $24 \mathrm{kWh}$ capacity battery taking 25 - 30 minutes, usage frequencies of $10+$ per day would likely be accommodated without queuing and in this regard the fast charging network would appear adequate at current levels. However from both a density and a maximum allowable travel distance to a fast charging unit perspective, the network may be vulnerable in some areas. 


\section{CONCLUSIONS}

2 This research analysed the entire fast charging network in Ireland based on live usage statistics 3 over an extended period. A spatial analysis was carried out on the fast charging events in order 4 to determine the way in which EV users access the infrastructure. It was found that the fast 5 charging infrastructure was being used in a manner that may not have been intended or 6 anticipated by the infrastructure manufacturers or those responsible for its installation, with the 7 majority of fast charging events taking place less than $50 \mathrm{~km}$ from the EV users' home location. 8 Additional analysis was carried out comparing different geographic groups of EV users and 9 differences in usage patterns of the fast charging facilities were identified. Urban users were found to use the fast charging infrastructure in a very different manner to users based in rural city and county locations. The fast charging facilities in urban areas were used in a more local manner close to the users' home and this behaviour equated to local range extension or convenience charging. In comparison, rural city- and county-based EV users tend to charge further away from their home locations and use the fast charging facilities in a manner in line with the literature - as a means of extending the range or journey length undertaken with their vehicles. This urban/rural divide was not expected and has not been reported previously in the literature - it is hoped that this study will contribute to filling this gap internationally for future infrastructure development particularly in countries and states with similar demographics to Ireland.

The most common strategy for the rollout of EV charging infrastructure reported in the literature (and in particular fast charging facilities) is the 'highway corridor' approach. However, based on the observations in this study, it would appear that a strategy for the rollout of fast charging infrastructure should be to locate more facilities close to large urban or population centres in addition to on interurban highway corridors. One final point to note is that the first wave of EV owners or 'early adopters' may not use the infrastructure in the same way that subsequent users would and therefore further research on charging behaviour will be required as market penetration increases.

\section{ACKNOWLEDGEMENTS}

The authors wish to acknowledge the Electricity Supply Board of Ireland (ESB) and, in particular, their eCars group, who provided the charging data used in this analysis. The authors would also like to acknowledge Ordinance Survey Ireland (OSi) and the members of their mapping team for the provision of their Prime2 dataset. 


\section{REFERENCES}

1. Schroeder, A. and T. Traber, The Economics of Fast Charging Infrastructure for Electric Vehicles. Energy Policy, Vol. 43, 2012. pp. 136-144.

2. Usmani, O. and H. Rösler. Deliverable 9.7 - Policy recommendations and stakeholder actions towards effective integration of EVs in the EU. Green eMotion project published document: http://www.greenemotionproject.eu/upload/pdf/deliverables/D9_7-Policy-recommendations-and-stakeholderactions_submitted_c.pdf . 2015. Accessed July 31, 2015

3. Anegawa, T., 2010. Needs of Public Charging Infrastructure and Strategy of Deployment. Tokyo, Tokyo Electric Power Company, Inc. (TEPCO).

4. Celli, G., G.G. Soma, F. Pilo, F., Lacu, S. Mocci, and N. Natale, N. Aggregated electric vehicles load profiles with fast charging stations. Proceedings of the Power Systems Computation Conference (PSCC), Wroclaw, Poland 18 - 22 Aug 2014

5. NERL, California Statewide Plug-in Electric Vehicle Infrastructure Assessment . Alternative and Renewable Fuel and Vehicle Technology Program - Final Project Report. Published Document. Available from: California Energy Commission, Sacramento, CA 95814-5512, 2014. USA.

6. Axsen, J. and K. S. Kurani. Anticipating Plug-in Hybrid Vehicle Energy Impacts in California: Constructing Consumer-Informed Recharge Profiles. Transportation Research Part D: Transport and Environment. Vol 15, No. 4: 2010. pp. 212-219.

7. Sadeghi-Barzani, P., A. Rajabi-Ghahnavieh, and H. Kazemi-Karegar, Optimal fast charging station placing and sizing. Applied Energy, Vol. 125, 2014. pp. 289-299

8. Dimitrios, E., C. Antoniou, Y. Tyrinopoylos, Y. and E. Mitsakis, Spatial Exploration of Effective Electric Vehicle Infrastructure Location. Procedia - Social and Behavioral Sciences, Vol. 48, 2012. pp.765-774.

9. Chen, T. D., K. M. Kockelman, and M. Khan, The electric vehicle charging station location problem: A parking-based assignment method for Seattle. Transportation Research Board of the National Academies, Washington D.C. 2013.

10. Nicholas, M.A., G. Tal, J. Davies and J. Woodjack, DC Fast as the Only Public Charging Option? Scenario Testing from GPS Tracked Vehicles. Transportation Research Board of the National Academies, Washington D.C. 2012.

11. Sathaye, N. and S. Kelley. An approach for the optimal planning of electric vehicle infrastructure for highway corridors. Transportation Research Part E: Logistics and Transportation Review, Vol. 59, Issue C, 2013. pp 15-33

12. Nicholas, M.A., G. Tal, G, and J. Woodjack, California Statewide Charging Assessment Model for Plug-in Electric Vehicles: Learning from Statewide Travel Surveys. Working Paper (Jan, 29th 2013), Institute of Transportation Studies, University of California, Davis.

13. Jia L., Z. Hu, W. Liang, W. Tang, and Y. Song, A Novel Approach for Urban Electric Vehicle Charging Facility Planning Considering Combination of Slow and Fast Charging. Proceedings of the International Conference on Power System Technology (POWERCON, 2014), Chengdu, China, 20-22 Oct. 2014.

14. Bayram, I.S., G. Michailidis, M. Devetsikiotis, and F. Granelli. Electric Power Allocation in a Network of Fast Charging Stations. IEEE Journal on Selected Areas in Communications, Vol. 31, No. 7, 2013. pp.1235-1246.

15. Smart, J. and J. Francfort Charging Infrastructure Use Profiles and Installation Costs for 17,000 Units". Transportation Research Board of the National Academies Washington D.C. Annual Meeting. 2015 
16. CSO. This is Ireland, Highlights from Census 2011 Part 1. Published Report. Central Statistics Office, Skehard Road, Cork T12 X00E, Ireland. 2012.

17. ESB, (2013). Europe's First Cross-Border EV Fast Charger Network Launched. Available at: http://www.esb.ie/electric-cars/electric-car-news-and-events/electric-carpress-releases/fast-charge-network.jsp [Accessed 30/07/2015].

18. OSi. Prime2 - Data Concepts \& Data Model Overview. Published Document. Ordinance Survey Ireland, Phoenix Park, Dublin 8. 2014.

19. ESRI. ArcGIS Desktop: Release 10.1. Environmental Systems Research Institute, Redlands, CA, USA, 2014.

20. ISO. ISO 19115-1:2014 Geographic information -- Metadata -- Part 1: Fundamentals”. Published Document. International Organization for Standardization, 1214 Vernier, Geneva, Switzerland. 2014.

21. ISO. ISO 14825:2011 - Intelligent transport systems -- Geographic Data Files (GDF) - GDF5.0. Published Document. International Organization for Standardization, 1214 Vernier, Geneva, Switzerland. 2011.

22. ESRI, 2015. ESRI Support-GIS Dictionary - Impedance. [Online] Available at: http://support.esri.com/en/knowledgebase/GISDictionary/term/impedance [Accessed 04 November 2015].

23. SEAI, SEAI Energy in Transport: 2014 Report. Published Report; Sustainable Energy Authority of Ireland, Dublin, Ireland. 2014. 